\title{
Biliary Ascaris with Obstructive Joundice in Ethiopia : A Case Report
}

\section{Zerubabel Tegegne Desita}

Assistant Professor (Radiologist), University of Gondar, ETHIOPIA

\begin{abstract}
A 28 years old female Ethiopian (black) patient presented with epigastric pain and jaundice since a week from presentation. Laboratory examination showed ova of ascaris on stool examination and +3 bilirubin on urine analysis and elevated direct and total serum bilirubin. Ultrasound of the abdomen showed tubular long mobile worms within the gallbladder and bile ducts with intra hepatic bile ducts dilatation. With sonographic diagnosis of biliary ascaris the patient was given mebendazol and got symptomatic improvement. Follow up ultra sound after treatment showed improved abnormal findings. Detail of the case is discussed.
\end{abstract}

Key Words: Ascaris; Biliary ascaris; Ultrasound

6/30/2015 Source of Support: Nil, Conflict of Interest: No competing interest to declare
How to Cite: Desita ZT. (2015) Biliary Ascaris with Obstructive Joundice in Ethiopia: A Case Report. Malaysian Journal of Medical and Biological
Research, 2(1), 19-22.
$\begin{aligned} & \text { This article is is licensed under a Creative Commons Attribution-NonCommercial 4.0 International License. } \\ & \text { Attribution-NonCommercial (CC BY-NC) license lets others remix, tweak, and build upon work non-commercially, and although the new works must also CC) } \\ & \text { acknowledge \& be non-commercial. }\end{aligned}$

\section{INTRODUCTION}

Ascaris is the most common helminthes infection of human beings with a worldwide prevalence of $25 \%$ worldwide causing 20,000 deaths per year (1). It is common in the tropics and the developing countries. Transmission is by orofecal route associated \& more common in children (2).Though it is an intestinal parasite the worm can migrate to extra intestinal organs like the biliary system. Biliary ascaris is rare but is reported to occur in endemic regions like Far East, India, and Latin America. Biliary ascariasis is symptomatic as biliary colic. There are complications associated with biliary ascaris including cholecystitis, cholangitis, pancreatitis on acute phases; and stone formation, biliary stricture and cholangiocarcinoma lately (3).

Diagnosis of biliary ascaris is by ultrasound examination of the abdomen which can show a mobile worm with echogenic wall and central hypoechogenicity in the bile ducts and gall bladder being sensitive up to $86 \%$ (1).

Treatment of biliary ascariasis depends on the location of the worm and presence of complications. Conservative treatment is first choice of treatment as there is a possibility of spontaneous worm movement out of the biliary tree. Antihelminthic treatment is reserved till worms move out of the biliary tree. Endoscopic removal of worms is recommended when conservative management fails and ascaris worms remain in the CBD. Surgery is reserved for ascaris confined to the gall bladder and in complicated cases $(2,4)$.

\section{Case Presentation}

A 28 years old female Ethiopian (black) patient presented with a chief compliant of epigastric burning pain and yellowish discoloration of the eye with reddish discoloration of urine since a week from presentation. She had a history of recurrent malarial attack. On physical examination the patient had yellowish discoloration of the eye and skin. Laboratory examination showed ova of ascaris and hook worm on stool examination and many WBCs/HPF and +3 bilirubin on urine analysis. Liver function test showed elevated direct and total bilirubin.

Ultrasound of the abdomen upon presentation showed mobile worm with echogenic wall and central hypoechogenicity in the CBD and gallbladder with dilated intrahepatic bile ducts (Fig. 1, 2, 3). Mild hepatosplenomegally seen with normal echo texture. With this finding diagnosis of biliary ascaris with bile duct obstruction is made.

The patient was given mebendazol PO for 3 days and returned back after two weeks with marked symptomatic improvement associated with passage of many dead ascaris worms with stool and with disappearance of yellowish discoloration of the eye \& skin. Follow up ultrasound on the date of return of the patient showed improved abnormalities seen previously except persistent splenomegally (Fig.4). 


\section{Discussion}

This patient is diagnosed to have biliary acariasis by sonographic examination with typical sonographic findings of biliary ascaris and biliary obstruction. Stool exam, U/A and LFT findings was supportive of the sonographic finding.

Conservative management is ignored in this patient and inappropriate PO antihelminthic treatment was given while worms are within the bile ducts. But the patient got improvement both clinically and on imaging. If the worms would die within the biliary tree upon antihelminthic drug administration the patient could be at risk of developing complications like stricture and stone formation at the biliary tree.

None of the complications of biliary ascaris was seen in both the initial and the follow up ultrasound examination.

This case shows occurrence of biliary ascaris in Ethiopia as in other endemic areas of ascaris in the world which improved with PO mebendazol administration.

COMPETING INTEREST: The authors declare that they have no competing interest.

ETHICAL ISSUE: Verbal consent was taken from the patient and ethical clearance and permission to publish the case was obtained from the hospital administration.

\section{ACKNOWLEDGEMENT}

The author acknowledgement goes to the patient who volunteered her story to be written as case report and to UOG Hospital administration for evaluating the case and giving ethical clearance.

\section{ABBREVIATIONS}

UOG (University of GONDAR), WBC/HPF (white blood cell per high power field), CBD (common bile duct), PO (per oral), UA (urin analysis), LFT (liver function test)

\section{REFERENCES}

Ali YM, Sarwar JM, Sarker MC, Hossain MS, Kayes MN, Rahman MM and Hainz H. 2014. Core Decompression by Laser Osteoperforation: A Preliminary Report of New and Minimally Invasive Modality for the Treatment of Avascular Necrosis of the Femoral Head Malaysian Journal of Medical and Biological Research, 1, 9-17.

David R Haburchak, MD, Program Director, Professor, Department of Internal Medicine, Division of Infectious Disease, Medical College of Georgia; Ascariasis, www.eMedicine.com

Ersöz Galip, Üstün Şebnem, Dağcı Hande Ege University School of Medicine, Departments of Gastroenterology, and Parasitology Obstructive jaundice and acute pancreatitis due to biliary ascariasis

FM Sanai, MA Al-Karawi; Saudi journal of gastroenterology. Year : 2007 Vol. 13, Issue 1, Page (25-32)

Sanai FM, Al-Karawi MA. Biliary ascariasis: Report of a complicated case and literature review. Saudi J Gastroenterol 2007; 13:2532. 


\section{Figures}

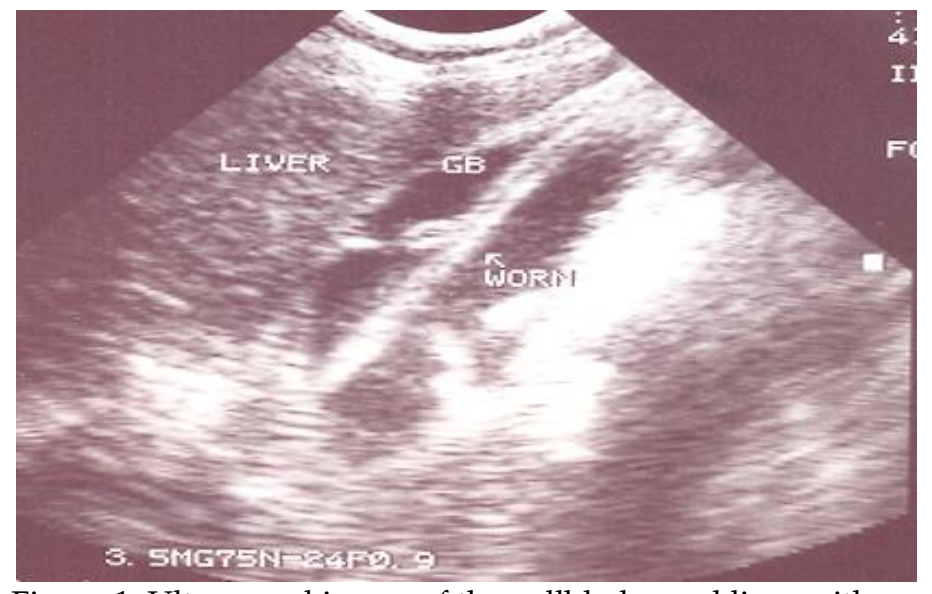

Figure 1: Ultrasound image of the gallblader and liver with ascaris worm within the gallblader; real-time image showed mobility of the worm

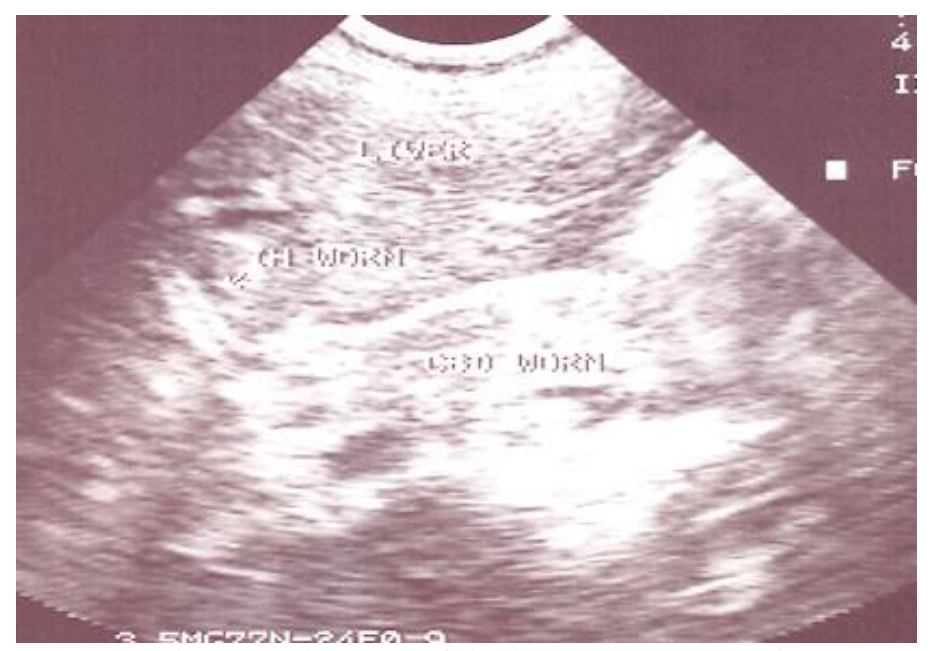

Figure 2: Ultrasound image of the liver and CBD with ascaris worm within the CBD and hepatic ducts

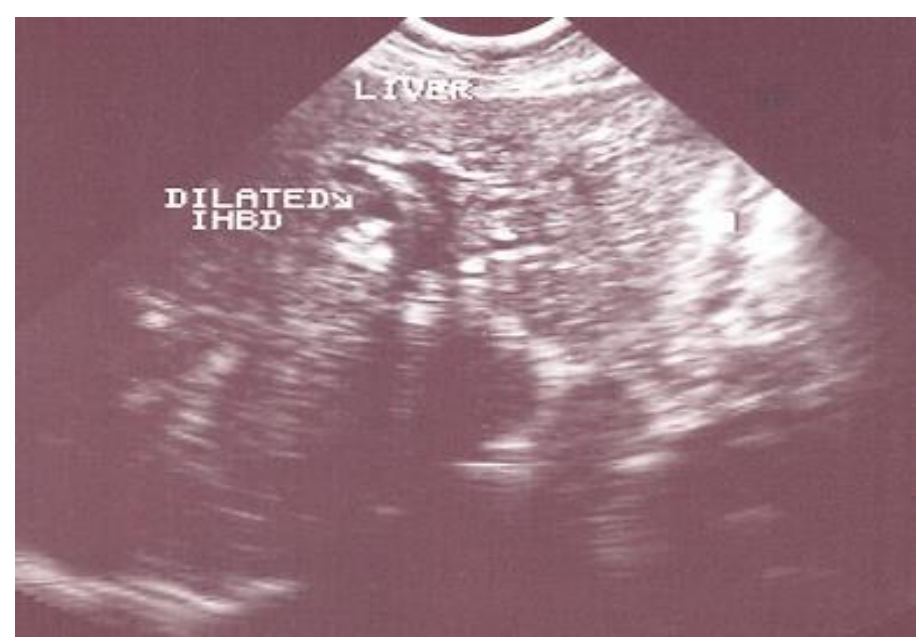

Figure 3: Ultrasound image of the liver with dilated intra hepatic bile ducts 


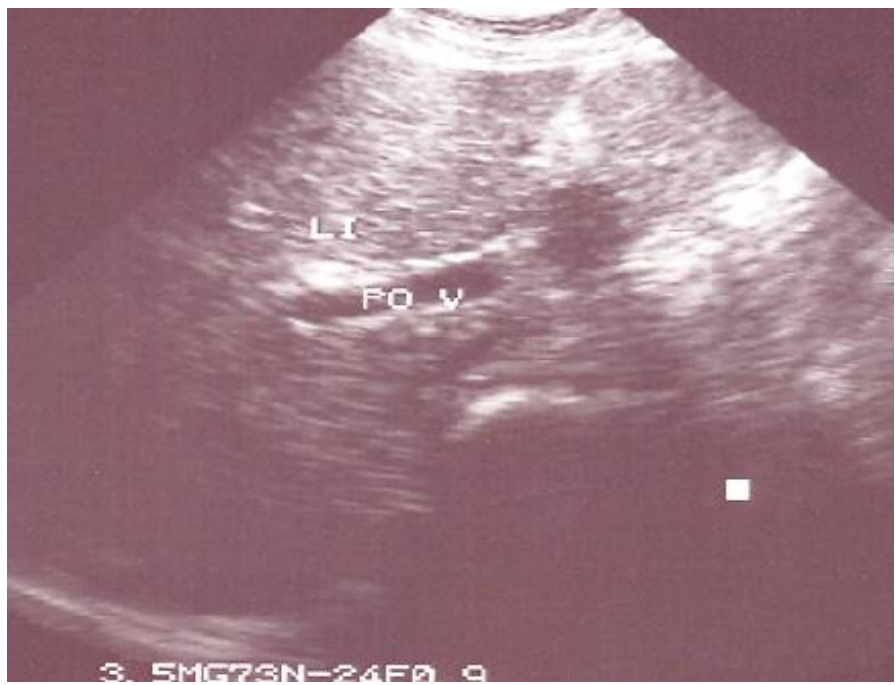

Figure 4: Ultrasound image of the liver after passage of ascaris worm (improved)

-- 0 -- 